\title{
Influence of Hold Time on Creep-Fatigue Behavior of an Advanced Austenitic Alloy
}

Mark Carroll

Laura Carroll

September 2011

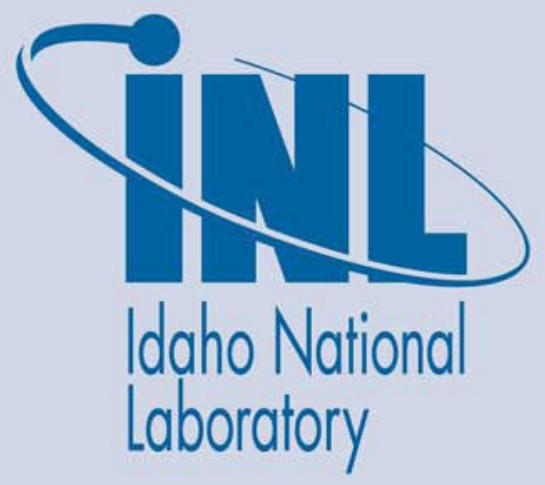

The INL is a U.S. Department of Energy National Laboratory operated by Battelle Energy Alliance 


\section{DISCLAIMER}

This information was prepared as an account of work sponsored by an agency of the U.S. Government. Neither the U.S. Government nor any agency thereof, nor any of their employees, makes any warranty, expressed or implied, or assumes any legal liability or responsibility for the accuracy, completeness, or usefulness, of any information, apparatus, product, or process disclosed, or represents that its use would not infringe privately owned rights. References herein to any specific commercial product, process, or service by trade name, trade mark, manufacturer, or otherwise, does not necessarily constitute or imply its endorsement, recommendation, or favoring by the U.S. Government or any agency thereof. The views and opinions of authors expressed herein do not necessarily state or reflect those of the U.S. Government or any agency thereof. 


\title{
Influence of Hold Time on Creep-Fatigue Behavior of an Advanced Austenitic Alloy
}

\author{
Mark Carroll \\ Laura Carroll
}

September 2011

Idaho National Laboratory Idaho Falls, Idaho 83415

http://www.inl.gov

Prepared for the

U.S. Department of Energy

Office of Nuclear Energy

Under DOE Idaho Operations Office

Contract DE-AC07-05ID14517 



\begin{abstract}
An advanced austenitic alloy, HT-UPS (high-temperature ultrafineprecipitation-strengthened), has been identified as an ideal candidate material for the structural components of fast reactors and energy-conversion systems. HTUPS alloys demonstrate improved creep resistance relative to 316 stainless steel (SS) through additions of $\mathrm{Ti}$ and $\mathrm{Nb}$, which precipitate to form a widespread dispersion of stable nanoscale metallic carbide (MC) particles in the austenitic matrix. The low-cycle fatigue and creep-fatigue behaviors of an HT-UPS alloy have been investigated in air at $650{ }^{\circ} \mathrm{C}$ and $1.0 \%$ total strain, with an R-ratio of -1 and hold times as long as $9.0 \times 10^{3} \mathrm{sec}$ at peak tensile strain. The cyclic deformation response of HT-UPS is directly compared to that of standard 316 SS. The measured values for total cycles to failure are similar, despite differences in peak stress profiles and in qualitative observations of the deformed microstructures. Crack propagation is primarily transgranular in fatigue and creep-fatigue of both alloys at the investigated conditions. Internal grain boundary damage in the form of fine cracks resulting from the tensile hold is present for hold times of $3.6 \times 10^{3} \mathrm{sec}$ and longer, and substantially more internal cracks are quantifiable in $316 \mathrm{SS}$ than in HT-UPS. The dislocation substructures observed in the deformed material differ significantly; an equiaxed cellular structure is observed in $316 \mathrm{SS}$, whereas in HT-UPS the microstructure takes the form of widespread and relatively homogenous tangles of dislocations pinned by the nanoscale MC precipitates.
\end{abstract}




\section{ACKNOWLEDGEMENTS}

The authors would like to acknowledge Joel Simpson and Randy Lloyd for the mechanical testing, Julian Benz for the optical metallography, and Tammy Trowbridge for the SEM work, and Todd Morris for the metallurgical sample preparation. The authors would also like to thank Jeremy Busby, Yukinori Yamamoto, Sam Sham and Lizhen Tan at Oak Ridge National Laboratory (ORNL) both for supplying the hot rolled HT-UPS material and for thoughtful guidance and discussions regarding this subject matter. This work was supported through the U.S. Department of Energy Nuclear Energy. Transmission electron microscopy work performed in the Boise State Center for Materials Characterization has been supported by NSF MRI Grant DMR-0521315.

This document will also be submitted for publication to Acta Materialia. 


\section{CONTENTS}

ABSTRACT

ACKNOWLEDGEMENTS

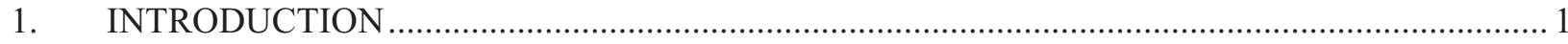

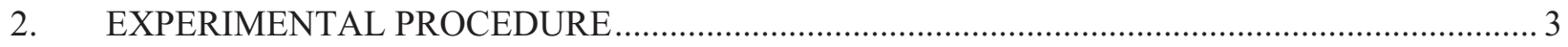

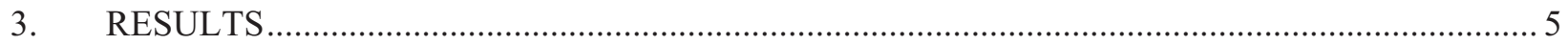

3.1 Characterization of the Base Material ................................................................................. 5

3.2 Fatigue and Creep-Fatigue Mechanical Behavior ........................................................... 7

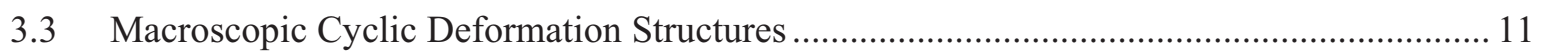

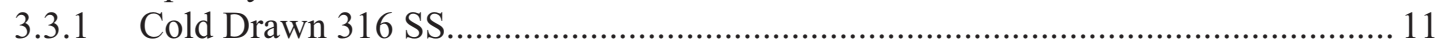

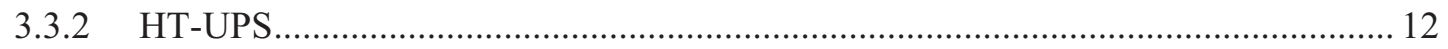

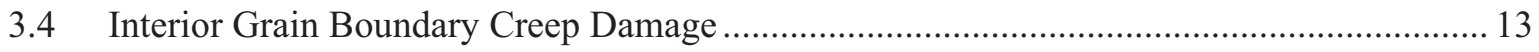

3.5 Cyclically Deformed Dislocation Structure ................................................................ 13

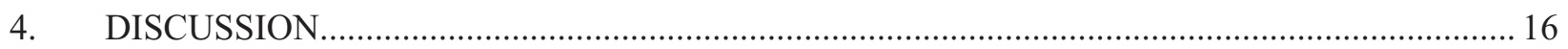

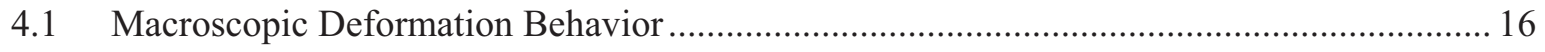

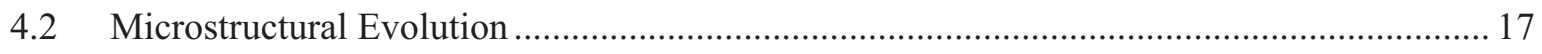

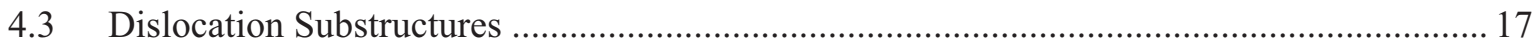

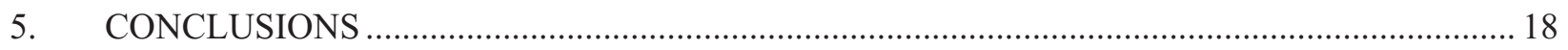

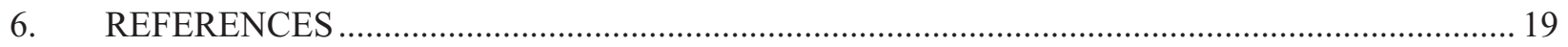

\section{FIGURES}

Figure 1. Nano-scale precipitates in the HT-UPS alloy demonstrate coherency with the matrix in the cubic orientation, as evidenced by the cuboidal Moiré fringe contrast. Image is taken slightly off of the [100] zone axis to enhance contrast.

Figure 2. Optical image (a) and transmission electron microscope image (b, c) of the as-received microstructure of the HT-UPS alloy......

Figure 3. Slip bands resulting from forming operations are readily visible in the grains of rolled 316 SS.

Figure 4. Fatigue and creep-fatigue at $650^{\circ} \mathrm{C}$ and a total strain range of $1.0 \%$ of HT-UPS, cold drawn (CD) $316 \mathrm{SS}$, and hot rolled (HR) $316 \mathrm{SS}$. Cycles to failure as a function of hold time (a), peak tensile stresses as a function of cycle for continuous cycling (b), peak tensile and compressive stresses for creep-fatigue with a $1.8 \times 10^{3} \mathrm{sec}$ hold (c).

Figure 5. Hysteresis loops from low cycle fatigue deformation of HT-UPS (a) and 316 stainless steel (b) at $650^{\circ} \mathrm{C}$ and a $1 \%$ total strain. Hysteresis loops from creep-fatigue deformation of HT-UPS (c) and 316 stainless steel (d) at $650^{\circ} \mathrm{C}, 1 \%$ total strain, and a $1.8 \times 10^{3} \mathrm{sec}$ hold time. 
Figure 6. Creep-fatigue of 316 stainless steel (SS) and HT-UPS at $650^{\circ} \mathrm{C}$ and a $1.0 \%$ total strain with a $3.6 \times 10^{3} \mathrm{sec}$ hold. Midlife stress relaxation curves of HT-UPS and cold drawn (CD) $316 \mathrm{SS}$ (a). Relaxed stress, the stress at the completion of a hold period, and the peak tensile stress as a function of cycle (b).

Figure 7. Images of the macroscopic surface and interior cracking in creep-fatigue specimens tested at a $1 \%$ total strain range, $650^{\circ} \mathrm{C}$, and a $3.6 \times 10^{3}$ sec hold of CD $316 \mathrm{SS}(\mathrm{a}, \mathrm{c})$ and HT-UPS (b, d)

Figure 8. The oxide "pegs" (shallow oxide-filled surface regions) are prevalent in HT-UPS when held at elevated temperatures for cyclic testing.

Figure 9. Bright field transmission electron microscope (TEM) images of the equiaxed cellular structure formed during $(a, b)$ fatigue deformation of cold drawn 316 stainless steel and (c, d) $1.8 \times 10^{3} \mathrm{sec}$ hold creep-fatigue deformation.

Figure 10. Bright field transmission electron microscope (TEM) images of the dislocation substructure formed during fatigue deformation of HT-UPS $(a, b)$, creep fatigue deformation with a $3.6 \times 10^{3}$ sec hold time (c, d), and a $1.8 \times 10^{3}$ sec hold time (e). 15

\section{TABLES}

Table I. Compositions (in wt $\%$ ) of 316 stainless steel (SS) in the annealed, pickled and cold drawn (CD) and annealed, pickled, and hot rolled (HR) condition and a high temperature ultrafine-precipitate strengthened austenitic alloy (HT-UPS).

Table II. Fatigue and creep-fatigue cycle lifetimes and times to failure for HT-UPS, hot rolled (HR) $316 \mathrm{SS}$, and cold worked (CD) $316 \mathrm{SS}$ tested at $1.0 \%$ total strain and $650^{\circ} \mathrm{C}$. 


\section{Influence of Hold Time on Creep-Fatigue Behavior on an Advanced Austenitic Alloy}

\section{INTRODUCTION}

Advanced austenitic alloys are ideal candidate alloys for the structural components of fast reactors and energy-conversion systems, offering the potential for increased operating temperatures that increase cycle efficiency and for longer component lifetimes that reduce capital costs. Currently, the heat-resistant components in fast reactors consist primarily of standard austenitic stainless steels that operate in the temperature regime of 600 to $650{ }^{\circ} \mathrm{C}$ [1]. One type of advanced austenitic material that might replace the more conventional stainless steels is a high-temperature ultrafine-precipitation-strengthened (HT-UPS) alloy [2]. HT-UPS alloys offer improved strength and creep resistance over conventional stainless steels, particularly at temperatures in excess of $600{ }^{\circ} \mathrm{C}$ [2-4]. Developed in the 1980 s through a study to develop alloys for elevated temperature fossil fuel applications, HT-UPS has already been subjected to extensive studies covering the basic mechanical properties [2-5] and related microstructural evolution [6] following exposure to standard creep testing, but relatively little research has been carried out to specifically elucidate the combined creep-fatigue behavior of any of the HT-UPS variants [7]. In service, components will be subjected to pressure- and temperature-related stresses that are prone to fluctuations along with being held constant for extended periods of time. A thorough understanding of and predictive capability over these alloys will therefore rely more upon investigations that reveal the complex deformation reactions under creep-fatigue conditions, in which cyclic strains are interrupted by hold times at peak stress or strain values.

The HT-UPS alloys were specifically developed in order to provide a measurable improvement in creep resistance to the proven properties of 316 stainless steel (SS), which was addressed through minor compositional changes along with controlled additions of $\mathrm{Ti}$ and $\mathrm{Nb}$. These potent carbide-forming elements and the addition of a dedicated thermomechanical treatment (TMT) results in an alloy with an austenitic matrix containing a dispersion of ultra-fine MC carbides [2,3,5]. This finely-precipitated MC phase, which readily pins dislocations and prevents recovery of the deformed dislocation substructure [3], is reported to be rich in $\mathrm{Ti}$ and $\mathrm{Nb}[2,3,5]$ in HT-UPS alloys that are very similar in composition to the HT-UPS alloy investigated in this work. The fine MC precipitates are approximately 2 to $10 \mathrm{~nm}$ in diameter depending on the previous processing conditions and have a complex FCC crystal structure oriented in a cube-cube relationship with the austenitic matrix [6], characteristics that are confirmed (Figure 1) for the alloy being studied in this work. Larger $\mathrm{MC}$ and $\mathrm{M}_{23} \mathrm{C}_{6}$ precipitates, commonly seen in standard $316 \mathrm{SS}$, are present along the grain boundaries.

Despite the improved creep resistance documented in HT-UPS, these alloys have not been subjected to extensive oxidation testing, although the formation of deleterious oxide pegs following extended exposure to creep conditions has been reported [3]. For some applications, specifically sodium-cooled fast reactors, oxidation is not a concern as the main structural components are not exposed to an oxidizing environment. Regarding the material properties critical to these applications, the improved creep resistance is desired but is not be sufficient for predicting the response of components in actual service conditions. The direct impact of the improved creep resistance and fine dispersion of MC precipitates on the more complex creep-fatigue behavior of HT-UPS alloys is not well understood. 
As was described, isothermal strain-controlled creep-fatigue testing more closely approximates the thermally-induced cyclic loading that is interrupted by long periods of high temperature operation typical of reactor conditions. In this work, the creep-fatigue behavior of HT-UPS and 316 SS have been characterized and compared at $650{ }^{\circ} \mathrm{C}$, which is the expected in-service temperature of structural components in modern fast reactors. The macroscopic response to cyclic deformation and the resulting microstructural features that manifest themselves in both alloys are addressed. 


\section{EXPERIMENTAL PROCEDURE}

Material for cyclic testing was obtained from an experimental-scale heat of HT-UPS steel that was vacuum induction melted (VIM), and then electro-slag remelted, to make a $10 \mathrm{~cm}$ diameter ingot. The chemistry of the investigated HT-UPS alloy is given in Table I. Following a thermal anneal at $1200{ }^{\circ} \mathrm{C}$ for 4 hours in an argon atmosphere, the ingot was hot forged into plate at $1200{ }^{\circ} \mathrm{C}$ to a thickness of approximately $5 \mathrm{~cm}$ and then further hot rolled at $1200{ }^{\circ} \mathrm{C}$ to a thickness of $2 \mathrm{~cm}$, after which it was air cooled to room temperature. A thermomechanical treatment (TMT), including a solution anneal followed by a moderate level of cold work and aging, is typically performed in order to introduce matrix dislocations that serve as nucleation sites for the precipitation of the ultra-fine MC particles [2]. In this manner, the precipitation structure is already widespread throughout the matrix prior to employment of the material in the application. As a follow-on to work that was performed which demonstrates that precipitation of the ultra-fine particles will not occur until some level of deformation dislocation density has been established [6], the creep-fatigue testing and analysis reported here was conducted on material in the hot rolled condition with no addition of cold work. This condition allows for both full characterization in the un-precipitated state and for ex-situ observations of the precipitate morphology as deformation is introduced through fatigue and creep-fatigue exposure. To serve as a baseline alloy for comparison, 316 stainless steel (SS) was acquired both as round bar in the annealed, pickled, and cold drawn (CD) state and as plate in the annealed, pickled, and hot rolled (HR) condition. The compositions of the 316 SS heats are also given in Table I.

Straight-sided cylindrical specimens were tested in accordance with ASTM Standard E606-04, "Standard Practice for Strain-Controlled Fatigue Testing" [8] and ASTM Standard 2714-09, "Standard Method for Creep-Fatigue Testing" [9]. Fully reversed, strain-controlled continuous cycle fatigue and creep-fatigue testing were conducted at $650{ }^{\circ} \mathrm{C}$ in laboratory air with servo-hydraulic test frames. The continuous-cycle fatigue tests had a strain rate of $10^{-3} / \mathrm{sec}$ and a total strain range of $1 \%$. The creepfatigue tests followed a similar waveform as the standard fatigue test with the necessary hold time imposed at peak tensile strain. Hold times as short as $60 \mathrm{sec}$ and as long as $9.0 \times 10^{3} \mathrm{sec}$ were investigated. The number of cycles to initiation $\left(\mathrm{N}_{0}\right)$ and failure $\left(\mathrm{N}_{\mathrm{f}}\right)$ were defined based on the ratio of peak tensile stress to peak compressive stress. $\mathrm{N}_{0}$ is defined as the point at which the peak stress ratio initially deviates from the steady state value (or steadily declining values), while $\mathrm{N}_{10}$ is defined as a $10 \%$ drop in the ratio from $\mathrm{N}_{0}$ (the point of deviation) [9].

For metallurgical examination, the respective gage sections of the cyclically-deformed specimens were cut in half along the stress axis, or long axis of the specimen. The location for the longitudinal slice was carefully selected such that it traversed through the largest visible surface crack. The cut face was subsequently captured in a metallographic mount, polished, and etched to reveal surface features. Several different etchants were used in order to produce the most revealing contrast, including Vilella's reagent ( $20 \mathrm{ml}$ ethanol, $1 \mathrm{~g}$ picric acid, and $1 \mathrm{ml} \mathrm{HCl}$ ), oxalic acid, and a mixture of $\mathrm{H}_{2} \mathrm{O}, \mathrm{HCl}$, and $\mathrm{HNO}_{3}$ in a 3:3:1 ratio. The $316 \mathrm{SS}$ and HT-UPS material was also prepared for comparative metallographic examination in the undeformed, as-received state.

The remaining half of the gage section was utilized for the extraction of transmission electron microscopy (TEM) foils. The longitudinal portion of the gage section was mechanically reduced to approximately $125 \mu \mathrm{m}$ and then punched into $3 \mathrm{~mm}$ discs. The discs were electropolished using a twin jet TenuPol-5 polisher with a solution of $10 \%$ perchloric acid in ethanol at approximately $0{ }^{\circ} \mathrm{C}$. Microstructural characterization was conducted using a JOEL JEM-2010 HR Analytical TEM operating at $200 \mathrm{kV}$. 
Table I. Compositions (in wt\%) of 316 stainless steel (SS) in the annealed, pickled and cold drawn (CD) and annealed, pickled, and hot rolled (HR) condition and a high temperature ultrafine-precipitate strengthened austenitic alloy (HT-UPS).

\begin{tabular}{|l|c|c|c|c|c|c|c|c|c|c|c|}
\hline & $\mathrm{Fe}$ & $\mathrm{Cr}$ & $\mathrm{Mo}$ & $\mathrm{Nb}$ & $\mathrm{Ni}$ & $\mathrm{Mn}$ & $\mathrm{Ti}$ & $\mathrm{V}$ & $\mathrm{C}$ & $\mathrm{P}$ & $\mathrm{Si}$ \\
\hline CD 316 SS & Bal. & 17.1 & 2.1 & & 10.7 & 1.6 & 0.005 & & 0.02 & 0.03 & 0.37 \\
\hline HR 316 SS & Bal. & 16.8 & 2.1 & & 10.0 & 1.6 & & & 0.02 & 0.03 & 0.33 \\
\hline HT-UPS & 63.6 & 14.5 & 2.3 & 0.15 & 16.1 & 2.1 & 0.15 & 0.5 & 0.06 & 0.05 & 0.28 \\
\hline
\end{tabular}




\section{RESULTS}

\subsection{Characterization of the Base Material}

The microstructure of the as-received HT-UPS plate is relatively homogenous, as shown by the optical image perpendicular to the rolling direction shown in Figure 2(a). Not considering the effect of the prevalent annealing twins on the shape and aspect ratio of a number of the imaged grains, the overall grain size is approximately $75 \mu \mathrm{m}$. Cubodial $\mathrm{Ti}(\mathrm{C}, \mathrm{N})$ precipitates approximately $1 \mu \mathrm{m}$ on edge are present throughout, as are the common $\mathrm{Cr}_{23} \mathrm{C}_{6}$ precipitates decorating grain boundaries. TEM imaging revealed the notable absence of any of the ultra-fine MC precipitates, and showed various arrays of mobile dislocations within the austenitic grains, as shown in Figures 2(b) and 2(c). In the as-received state, no nanoscale MC carbides were observed to have precipitated at these dislocations.

The grain size of $316 \mathrm{SS}$ in the cold drawn condition (CD) is slightly smaller than that of the HTUPS hot-rolled plate. Evident in many of the grains of the CD material are slip lines attributable to deformation during the cold drawing operation, as shown in Figure 3. The hot rolled (HR) 316 SS plate grain size, by contrast, is considerably smaller at approximately $25 \mu \mathrm{m}$. Another observable feature is the volume fraction of sulfide stringers that can be observed running parallel to the rolling direction.

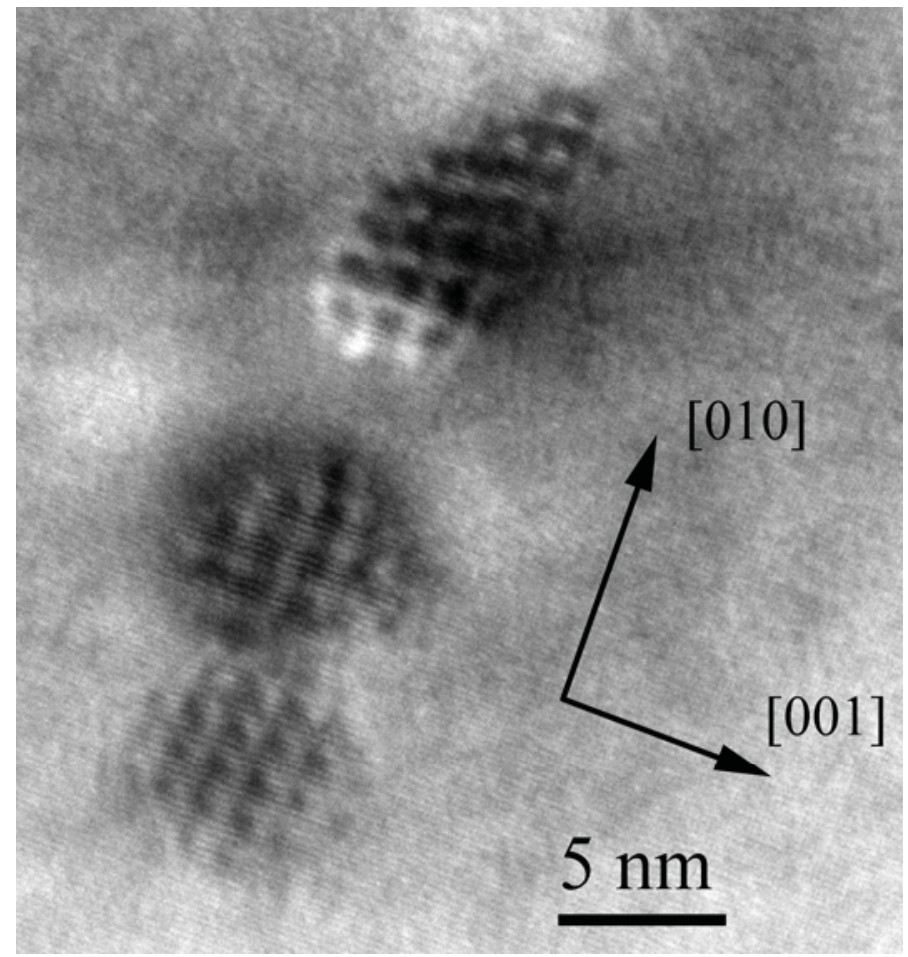

Figure 1. Nano-scale precipitates in the HT-UPS alloy demonstrate coherency with the matrix in the cubic orientation, as evidenced by the cuboidal Moiré fringe contrast. Image is taken slightly off of the [100] zone axis to enhance contrast. 


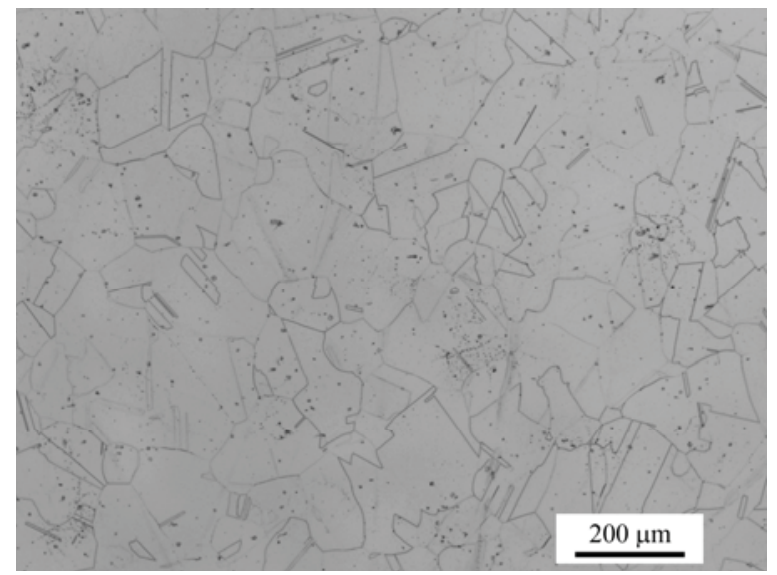

(a)

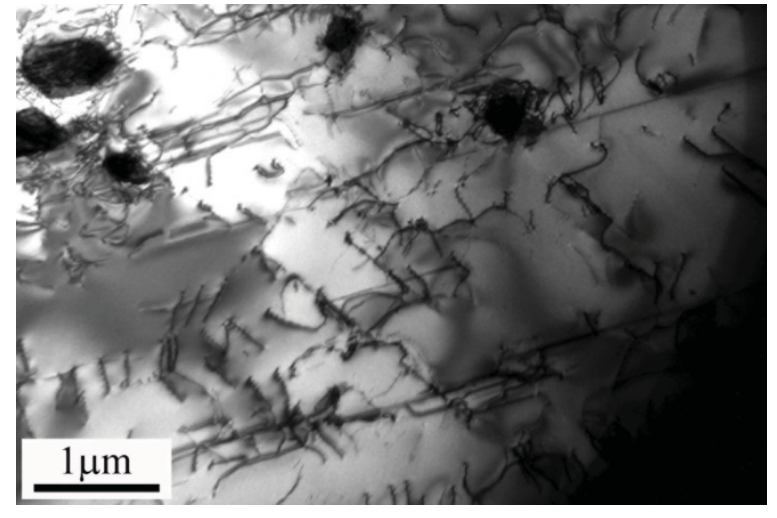

(b)

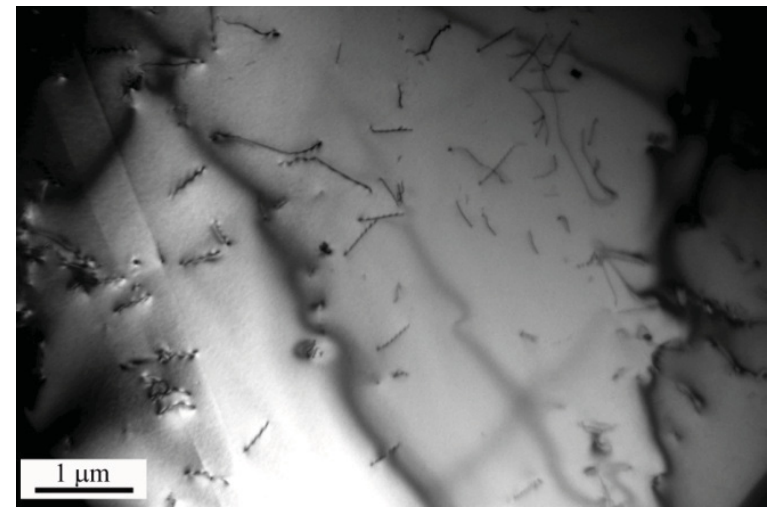

(c)

Figure 2. Optical image (a) and transmission electron microscope image (b, c) of the as-received microstructure of the HT-UPS alloy. 


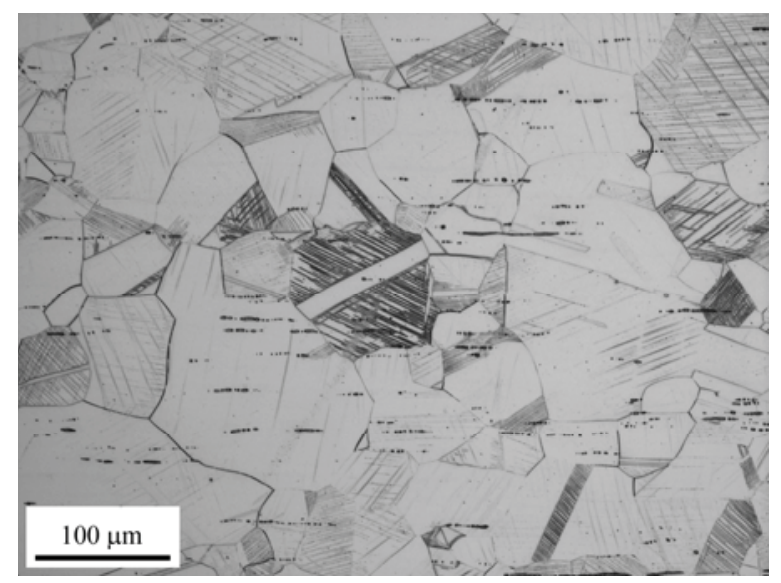

Figure 3. Slip bands resulting from forming operations are readily visible in the grains of rolled 316 SS.

\subsection{Fatigue and Creep-Fatigue Mechanical Behavior}

Extensive low-cycle fatigue and creep-fatigue testing of the 316 SS and HT-UPS was conducted on servo-hydraulic load frames. The quantified cycles-to-failure values in both fatigue and creep-fatigue of the HT-UPS and the 316 SS (both CD and HR) are similar, although the respective trends in deformation response during cycling is quite different. A summary of the fatigue and creep-fatigue results are given in Table II. Figure 4(a) is a plot of the cycles to failure as a function of hold time for the 316 SS and HTUPS at $650{ }^{\circ} \mathrm{C}$. Evident from this plot is the observation that increased hold times of up to $3.6 \times 10^{3} \mathrm{sec}$ did not degrade the creep-fatigue life of either alloy relative to continuous-cycle fatigue. Furthermore, a test with a $9.0 \times 10^{3} \mathrm{sec}$ hold time conducted on HT-UPS demonstrated that the lifetime with regard to cycles to failure is similar or better to that of the shorter hold time tests.

Despite the absence of a measurable difference in the cycles-to-failure values, the hardening behavior of the two alloys demonstrates considerable variation. The maximum and minimum stresses during both the continuous cycle and creep-fatigue tests with a $1.8 \times 10^{3} \mathrm{sec}$ hold are shown as a function of cycle in Figures 4(b) and 4(c), respectively. At the onset of continuous cycling, the HT-UPS alloy exhibits relatively low tensile and compressive peak stresses which quickly build up resulting from significant cyclic hardening. These stresses more than doubled during the first 60 cycles, increasing from $120 \mathrm{MPa}$ to $320 \mathrm{MPa}$, then continued to build slowly with increasing cycle counts until macrocrack initiation was noted. No steady state value is achieved at any point during the deformation process. The HR and CD 316 SS, by contrast, have considerably higher initial levels of peak stress of approximately $275 \mathrm{MPa}$, but further cycling beyond this peak value resulted in softening behavior. When a hold time is introduced, the creep-fatigue deformation exhibits similar behavior - except that HT-UPS demonstrates cyclic softening behavior beyond the peak value similar to that seen in 316 SS. Hysteresis loops for both CD 316 SS and HT-UPS are also an important indicator of differences in deformation behavior (shown in Figure 5 at cycles $1,10,100$, as well as for the midlife cycle) for both a fatigue test and a creep-fatigue test with a $1.8 \times 10^{3} \mathrm{sec}$ hold. The overall inelastic strain (the measured strain spread at zero stress) does not change significantly with increasing cycles in the CD $316 \mathrm{SS}$, while the cyclic hardening observed in the HTUPS steel is highly evident from the decreasing width of the hysteresis loops. 
Table II. Fatigue and creep-fatigue cycle lifetimes and times to failure for HT-UPS, hot rolled (HR) 316 SS, and cold worked (CD) $316 \mathrm{SS}$ tested at $1.0 \%$ total strain and $650^{\circ} \mathrm{C}$.

\begin{tabular}{|c|c|c|c|c|c|c|}
\hline Alloy & $\begin{array}{c}\text { Total } \\
\text { Strain } \\
\text { Range }\end{array}$ & $\begin{array}{c}\text { Midlife } \\
\text { Inelastic } \\
\text { Strain }\end{array}$ & $\begin{array}{c}\text { Tensile } \\
\text { Hold } \\
\text { Time }\end{array}$ & $\begin{array}{c}\text { Cycles } \\
\text { to } \\
\text { Initiation }\end{array}$ & $\begin{array}{c}\text { Cycles } \\
\text { to Failure }\end{array}$ & $\begin{array}{c}\text { Time to } \\
\text { Failure }\end{array}$ \\
\hline CW 316 & 1.0 & 0.67 & 0 & 947 & 1080 & 6 \\
\hline HR 316 & 1.0 & 0.57 & 0 & 1090 & 1143 & 6 \\
\hline HT-UPS & 1.0 & 0.55 & 0 & 586 & 1018 & 6 \\
\hline HR 316 & 1.0 & 0.68 & 180 & 970 & 1070 & 59 \\
\hline HR 316 & 1.0 & 0.66 & 180 & 953 & 1086 & 60 \\
\hline CW 316 & 1.0 & 0.72 & 300 & 283 & 1076 & 96 \\
\hline CW 316 & 1.0 & 0.69 & 600 & 1061 & 1248 & 215 \\
\hline HR 316 & 1.0 & 0.69 & 600 & 711 & 782 & 135 \\
\hline HT-UPS & 1.0 & 0.62 & 600 & 439 & 1042 & 179 \\
\hline CW 316 & 1.0 & 0.72 & 1800 & 783 & 947 & 479 \\
\hline HR 316 & 1.0 & 0.68 & 1800 & 585 & 637 & 322 \\
\hline HT-UPS & 1.0 & 0.65 & 1800 & 1174 & 1287 & 651 \\
\hline CW 316 & 1.0 & 0.73 & 3600 & 683 & 875 & 880 \\
\hline HR 316 & 1.0 & 0.66 & 3600 & 615 & 695 & 699 \\
\hline HT-UPS & 1.0 & 0.67 & 3600 & 626 & 880 & 885 \\
\hline HT-UPS & 1.0 & 0.63 & 9000 & $1370^{\mathrm{a}}$ & & 3433 \\
\hline
\end{tabular}




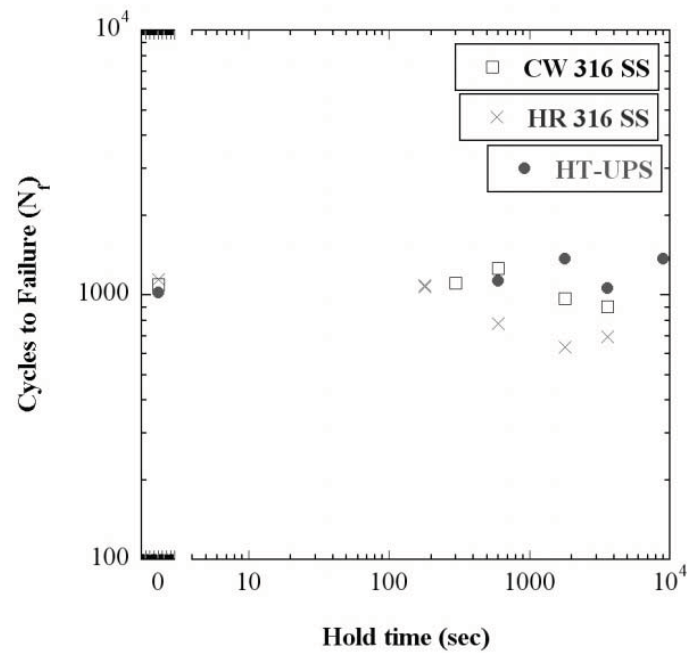

(a)

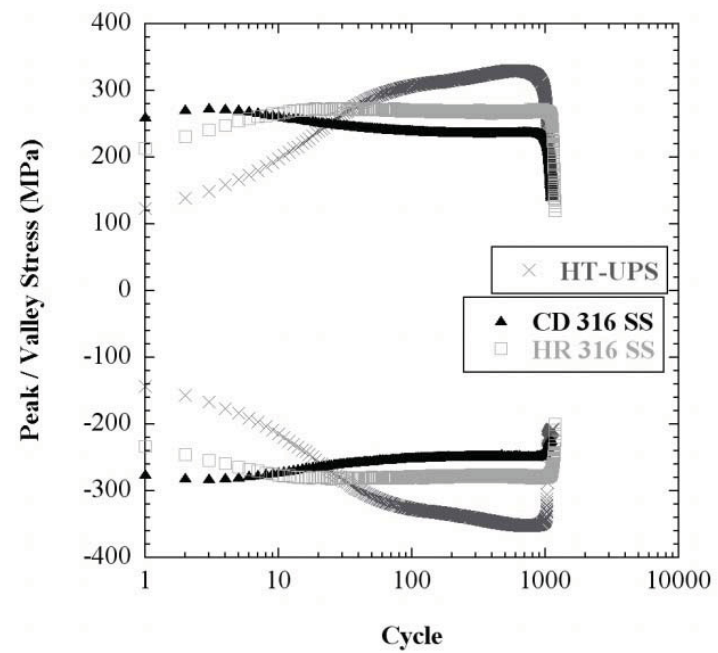

(b)

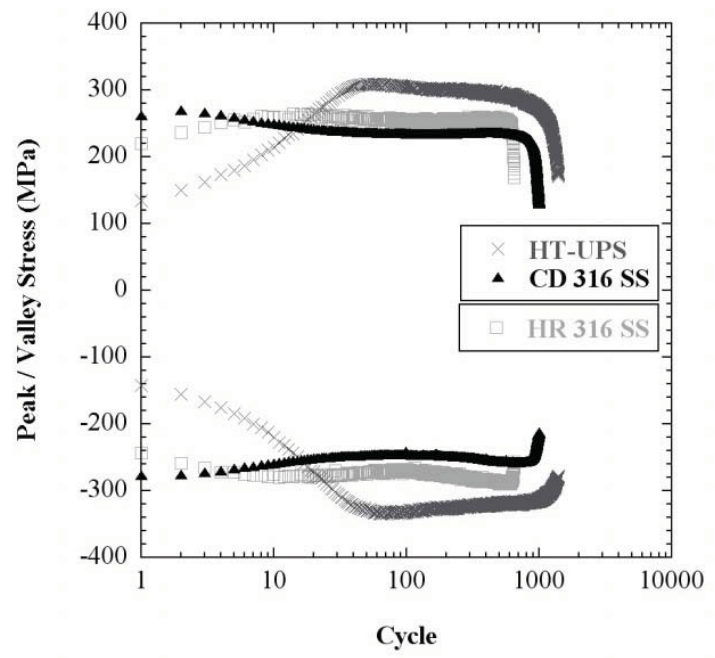

(c)

Figure 4. Fatigue and creep-fatigue at $650{ }^{\circ} \mathrm{C}$ and a total strain range of $1.0 \%$ of HT-UPS, cold drawn (CD) $316 \mathrm{SS}$, and hot rolled (HR) $316 \mathrm{SS}$. Cycles to failure as a function of hold time (a), peak tensile stresses as a function of cycle for continuous cycling (b), peak tensile and compressive stresses for creepfatigue with a $1.8 \times 10^{3} \mathrm{sec}$ hold (c). 


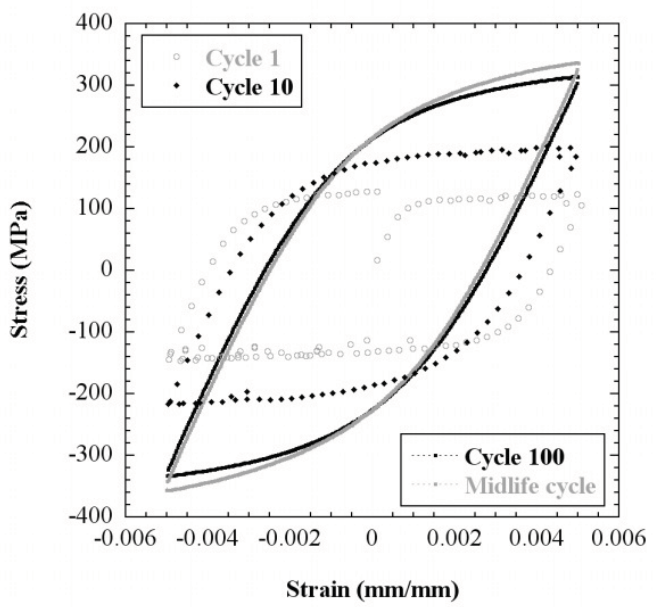

(a)

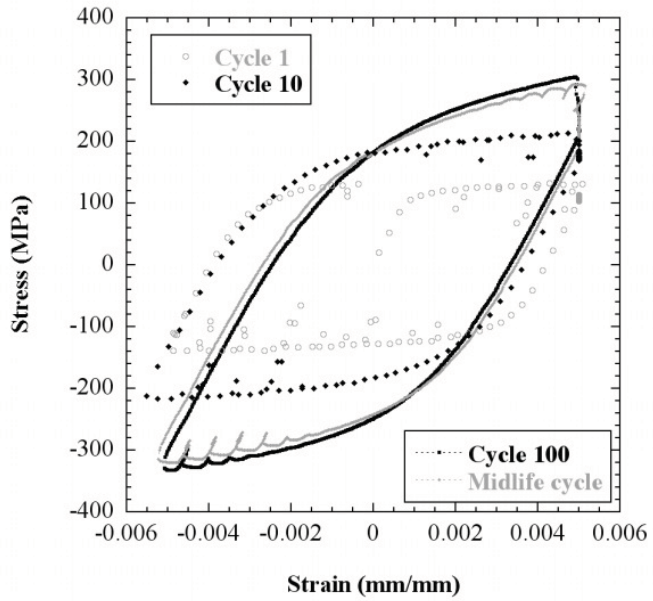

(c)

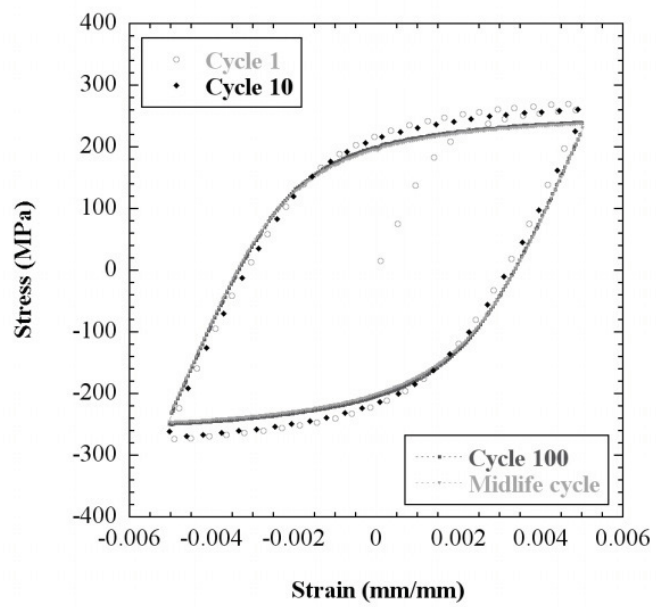

(b)

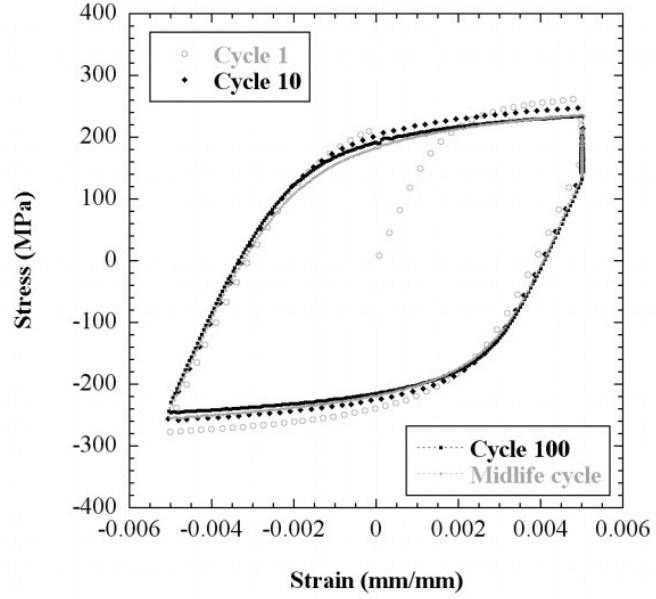

(d)

Figure 5. Hysteresis loops from low cycle fatigue deformation of HT-UPS (a) and 316 stainless steel (b) at $650^{\circ} \mathrm{C}$ and a $1 \%$ total strain. Hysteresis loops from creep-fatigue deformation of HT-UPS (c) and 316 stainless steel (d) at $650^{\circ} \mathrm{C}, 1 \%$ total strain, and a $1.8 \times 10^{3} \mathrm{sec}$ hold time. 
In the creep portion of the creep-fatigue cycle, the stresses clearly exhibit relaxation behavior, as shown in Figure 6(a) for a 3.6 $\times 10^{3} \mathrm{sec}$ hold time. Initially, the stresses relax rapidly, but relax at slower and slower rates toward the end of the hold time. The slope of the stress relaxation curves in the CD 316 SS following the initial rapid decrease is greater than that for HT-UPS, and continues to decrease at a more rapid rate until the end of the hold period. The relaxed stress, or stress at the termination of the hold, along with the peak tensile stress for each cycle of a creep-fatigue test at $650^{\circ} \mathrm{C}$ with a $3.6 \times 10^{3} \mathrm{sec}$ hold are shown in Figure 6(b). The stresses observed at the end of the hold period follow a similar pattern as the maximum stresses, with the differential stress between the peak and relaxed stress in CD $316 \mathrm{SS}$ being significantly higher than that of HT-UPS at all points of the cyclic test.

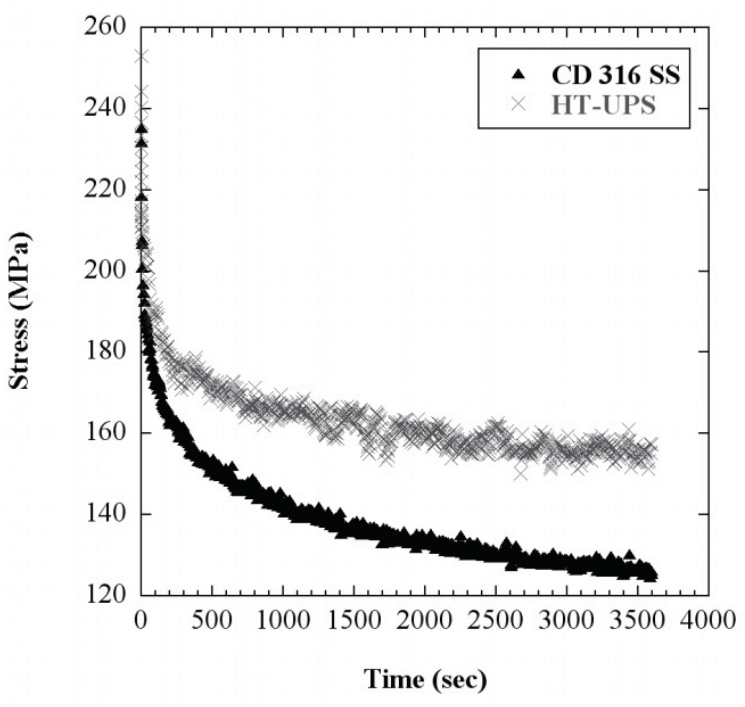

(a)

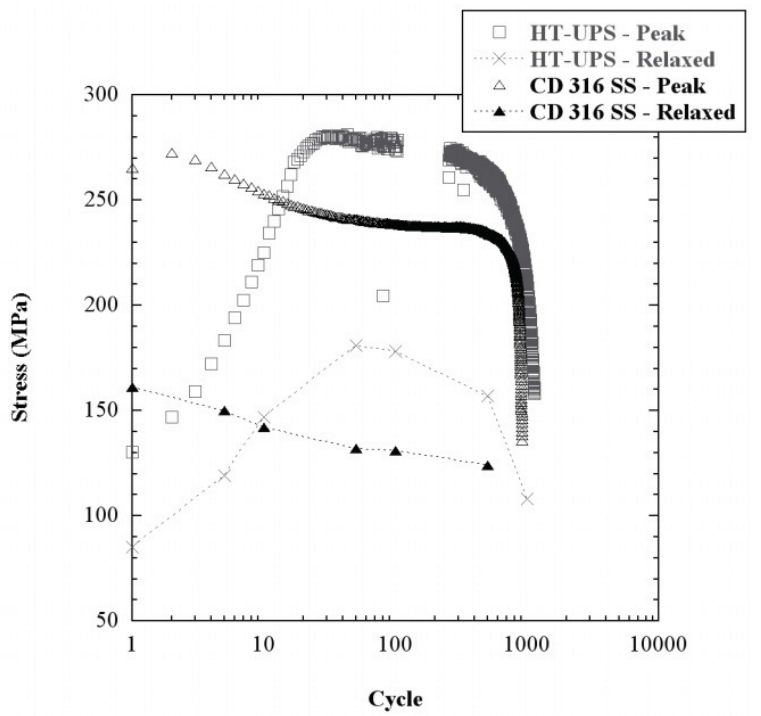

(b)

Figure 6. Creep-fatigue of 316 stainless steel (SS) and HT-UPS at $650{ }^{\circ} \mathrm{C}$ and a $1.0 \%$ total strain with a $3.6 \times 10^{3} \mathrm{sec}$ hold. Midlife stress relaxation curves of HT-UPS and cold drawn (CD) 316 SS (a). Relaxed stress, the stress at the completion of a hold period, and the peak tensile stress as a function of cycle (b).

\subsection{Macroscopic Cyclic Deformation Structures}

Metallurgical examination was conducted for the fatigue specimens as well as the creep-fatigue specimens with $600,1.8 \times 10^{3}$, and $3.6 \times 10^{3} \mathrm{sec}$ hold times. This subset of deformed specimens enabled direct comparison of the failure mechanisms based solely upon increasing hold times.

\subsubsection{Cold Drawn 316 SS}

Continuous cycling resulted in cracks initiating in a transgranular manner at the specimen surface, while creep-fatigue cycling resulted in intergranular surface crack initiation. In both the continuous-cycle and peak hold time specimens, propagation beyond the crack initiation is transgranular, as is shown in Figure 7 (a) for a $3.6 \times 10^{3} \mathrm{sec}$ creep-fatigue specimen. Shorter "secondary" cracks are also observed, and extend several grain diameters below the specimen surface. Branching of the cracks is clearly seen in all cases, particularly at grain boundary intersections. Despite this branching at oxidized grain boundaries, the cracks that continued to propagate were transgranular. The surface regions of both the primary and secondary cracks also exhibited an established oxide layer. Careful compositional analysis reveals that the oxide consists of two types; nearest the base metal, the oxide is rich in $\mathrm{Fe}, \mathrm{Cr}$, and $\mathrm{Ni}$, while sandwiched between the outer layers of $\mathrm{Fe}-\mathrm{Cr}-\mathrm{Ni}$ oxide is a Fe-rich oxide with relatively little $\mathrm{Cr}$ or $\mathrm{Ni}$. A small 
amount of $\mathrm{Mn}$ is also present in the form of discernable energy-dispersive spectroscopy (EDS) peaks in both types of oxide.

\subsubsection{HT-UPS}

The fatigued HT-UPS specimens exhibit widespread and very fine cracks along the specimen surface, initiating and propagating in a transgranular manner. No oxide is visible in optical microscope length scales. With the addition of a $600 \mathrm{sec}$ hold time, the resulting oxide layer on the crack surfaces is visibly thicker, as is shown in Figure 7(b), and the surface cracks initiated intergranularly. Similar to the CD 316 $\mathrm{SS}$, crack propagation is transgranular and a two-layer oxide is present (a Fe-rich oxide sandwiched between a Fe-Cr rich oxide). However, the intergranular surface oxidation and surface oxide, particular in the longer hold time tests, is much more extensive in HT-UPS than 316 SS. An image of intergranular surface oxidation at the specimen surface in a creep-fatigue specimen of HT-UPS with a $3.6 \times 10^{3} \mathrm{sec}$ hold time is shown in Figure 8.

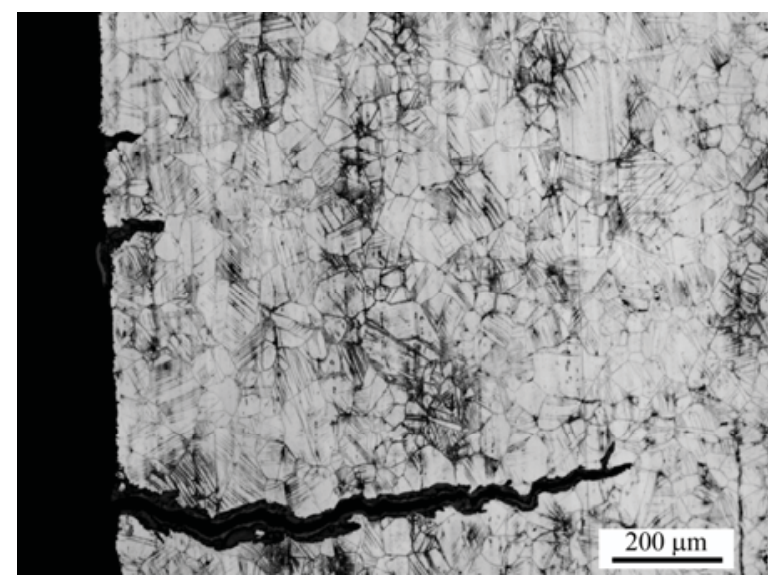

(a)

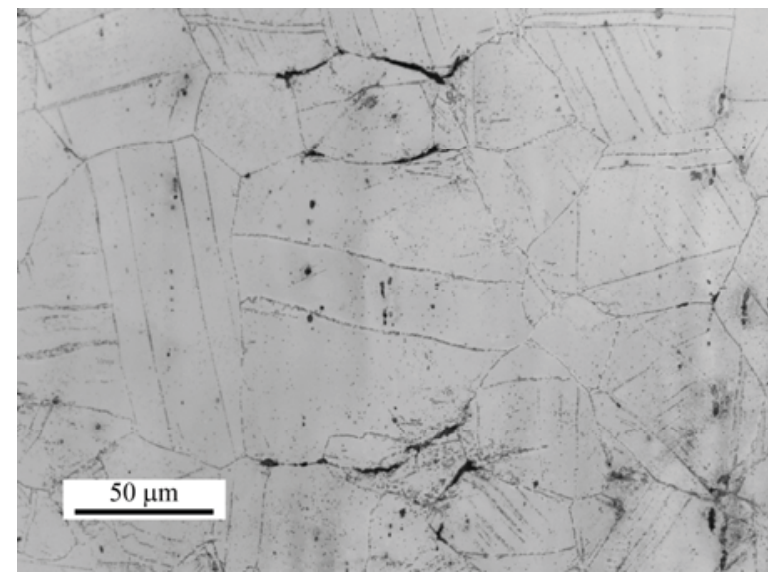

(c)

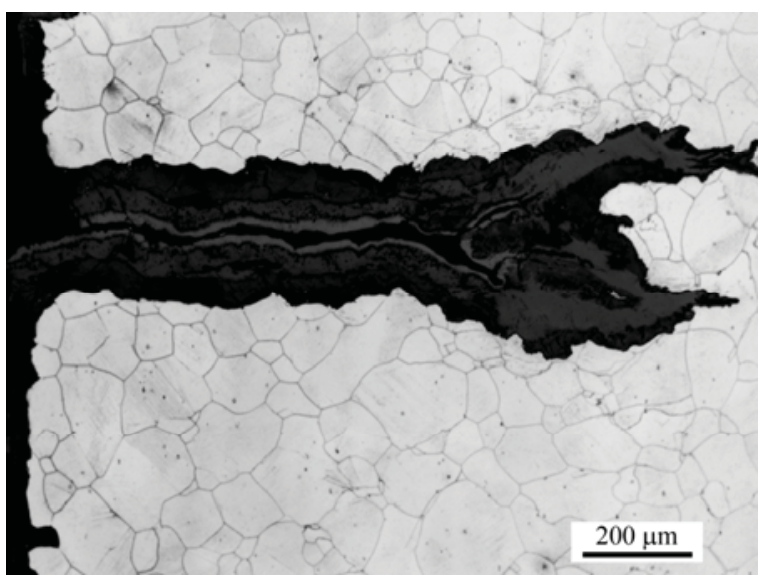

(b)

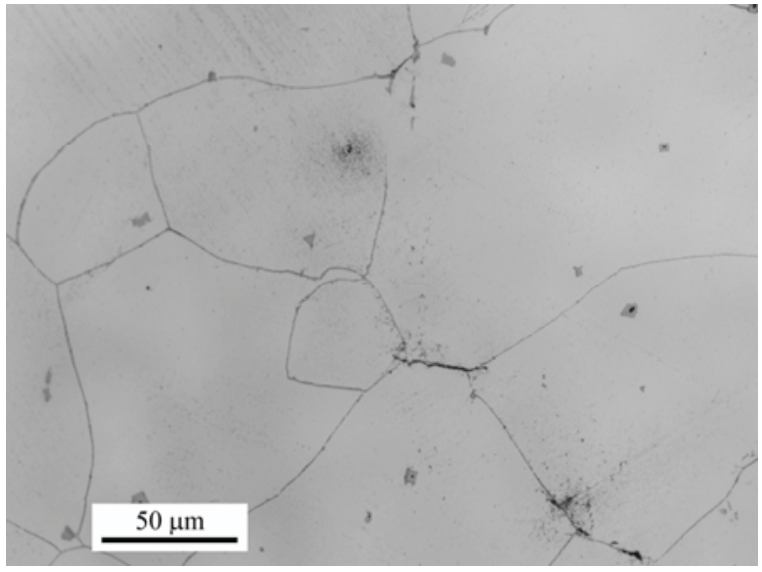

(d)

Figure 7. Images of the macroscopic surface and interior cracking in creep-fatigue specimens tested at a $1 \%$ total strain range, $650^{\circ} \mathrm{C}$, and a $3.6 \times 10^{3} \mathrm{sec}$ hold of CD $316 \mathrm{SS}(\mathrm{a}, \mathrm{c})$ and HT-UPS (b, d). 


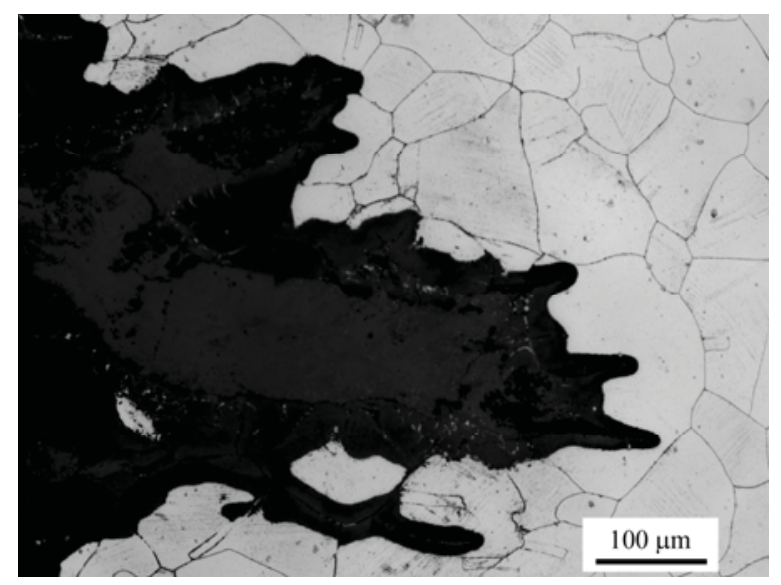

Figure 8. The oxide "pegs" (shallow oxide-filled surface regions) are prevalent in HT-UPS when held at elevated temperatures for cyclic testing.

\subsection{Interior Grain Boundary Creep Damage}

Damage specific to the grain boundaries in the bulk of the alloy is observed in the creep-fatigue specimens with tensile hold times of greater than $3.6 \times 10^{3} \mathrm{sec}$. Shorter peak tensile holds did not reveal any evidence of voids, cavitation, or cracking along the interior grain boundaries. The longer hold times, $3.6 \times 10^{3} \mathrm{sec}$ and $9.0 \times 10^{3} \mathrm{sec}$, resulted in interior grain boundary damage throughout the gage section. Figures 7(c) and 7(d) show examples of the fine interior cracks or cavitation seen in 316 SS and HTUPS, respectively. The length of the cavitation does not transcend the boundary of the single grain that it borders, and is typically less than $50 \mu \mathrm{m}$ overall. Of noteworthy importance is the observation that less interior grain boundary damage or cracking is present in the deformed HT-UPS alloy than the CD 316 SS.

\subsection{Cyclically Deformed Dislocation Structure}

The dislocation substructures that form during cyclic deformation of HT-UPS vary dramatically from those observed in 316 SS. Following pure simple fatigue deformation, an equilibrium dislocation cell structure with an approximate cell size of $1 \mu \mathrm{m}$ is prevalent in the CD $316 \mathrm{SS}$, as shown in Figures 9(a) and 9(b). The cell interiors have relatively few dislocations. By contrast, there is no clear picture of a cellular structure in the HT-UPS following fatigue deformation, as can be seen in Figures 10(a) and 10(b). In place of the clearly-defined cellular networks, there exist a multitude of dispersed and tangled dislocations interacting readily with the uniform dispersion of $5 \mathrm{~nm} \mathrm{MC}$ precipitates.

The gage sections of the CD 316 SS and HT-UPS cycled in creep-fatigue for $1.8 \times 10^{3}$ and $3.6 \times 10^{3}$ were also imaged. Again, $316 \mathrm{SS}$ CD has a clear, equiaxed cellular structure with cell boundaries, examples of which are shown in Figure 9(c) and 9(d). The cell boundaries consist of a well-defined dislocation networks, and, similar to what was seen in fatigue-tested specimens, relatively few mobile dislocations are present in the cell interiors. Conversely, the HT-UPS deformed in creep-fatigue again exhibited no evidence of any sort of cellular structure, and instead revealed a similar tangled dislocation density pinned by the prevalent dispersion of MC precipitates. Figure 10(c) is a bright-field TEM image showing the general distribution of fine MC precipitates (dislocations are purposely absent as a result of TEM imaging conditions). Figures $10(\mathrm{~d})$ and $10(\mathrm{e})$ reveal the large densities of pinned dislocations observed following creep-fatigue deformation. 


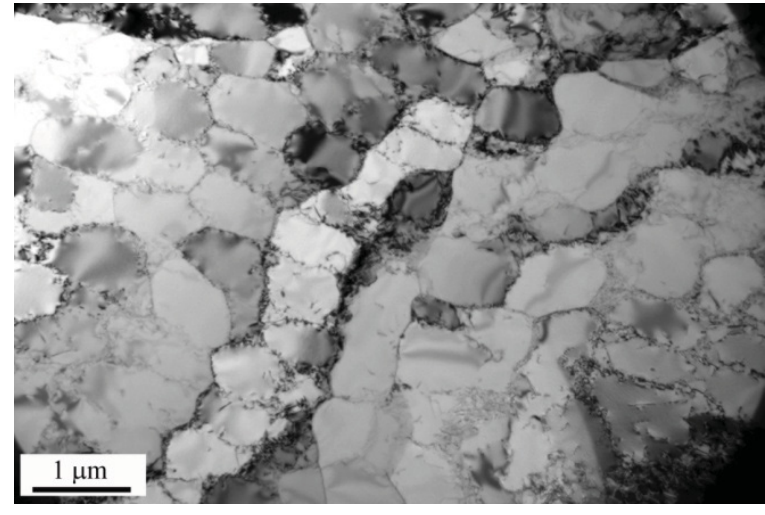

(a)

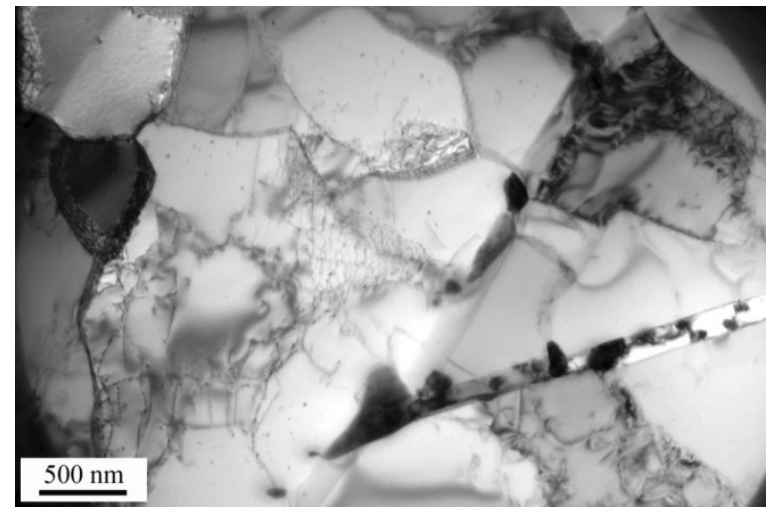

(c)

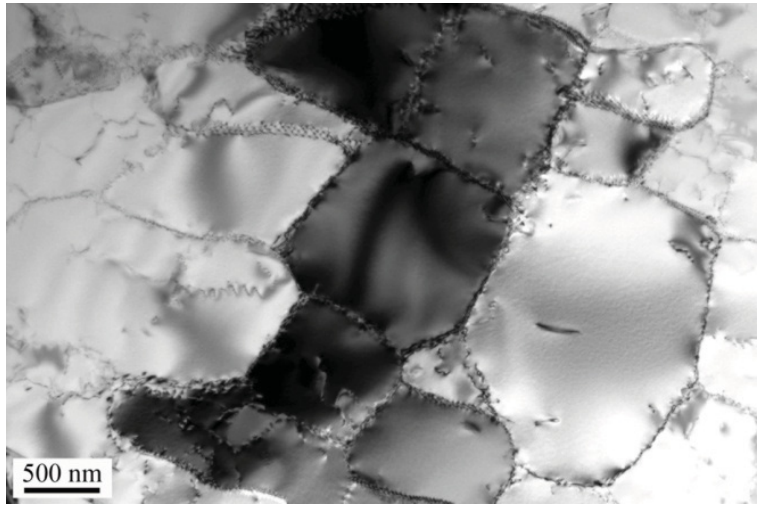

(b)

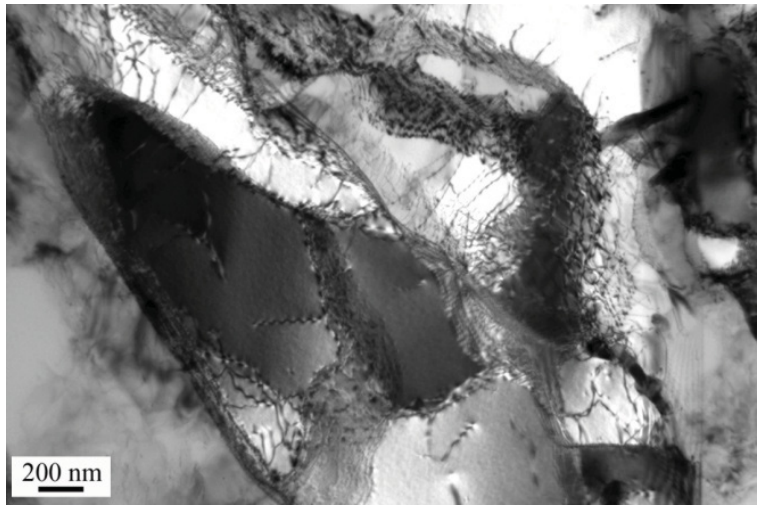

(d)

Figure 9. Bright field transmission electron microscope (TEM) images of the equiaxed cellular structure formed during $(\mathrm{a}, \mathrm{b})$ fatigue deformation of cold drawn 316 stainless steel and (c, d) $1.8 \times 10^{3} \mathrm{sec}$ hold creep-fatigue deformation. 


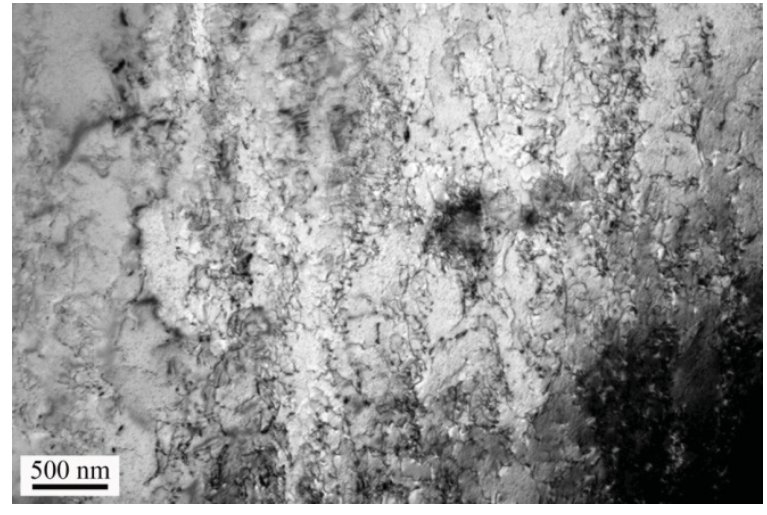

(a)

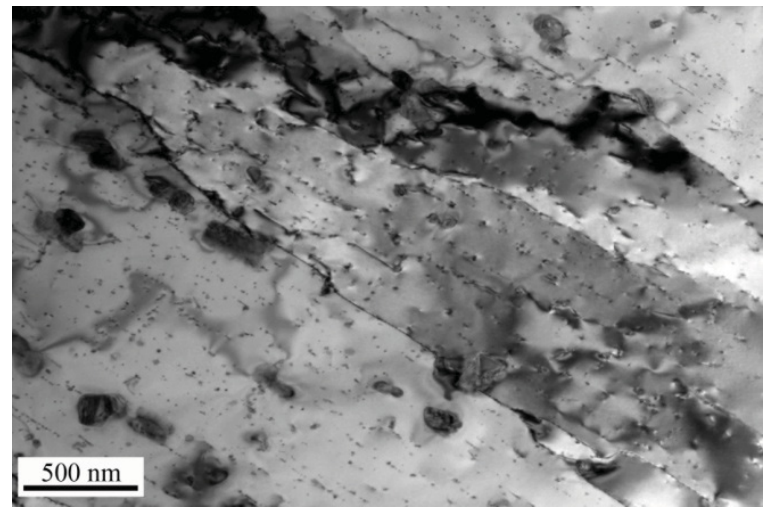

(c)

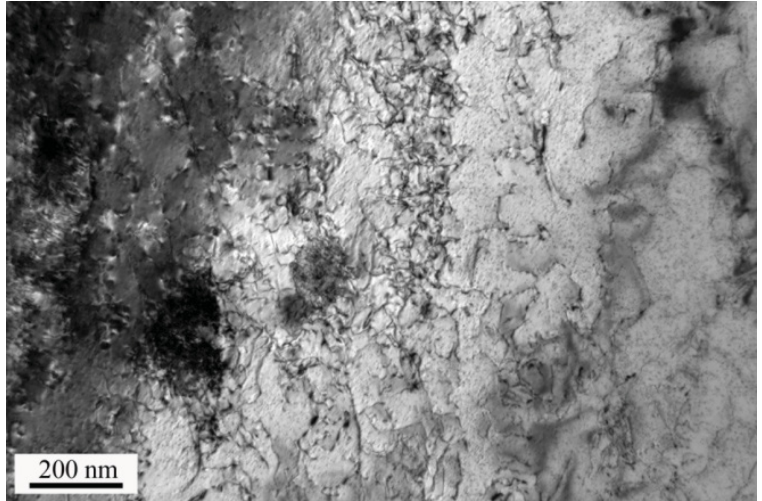

(b)

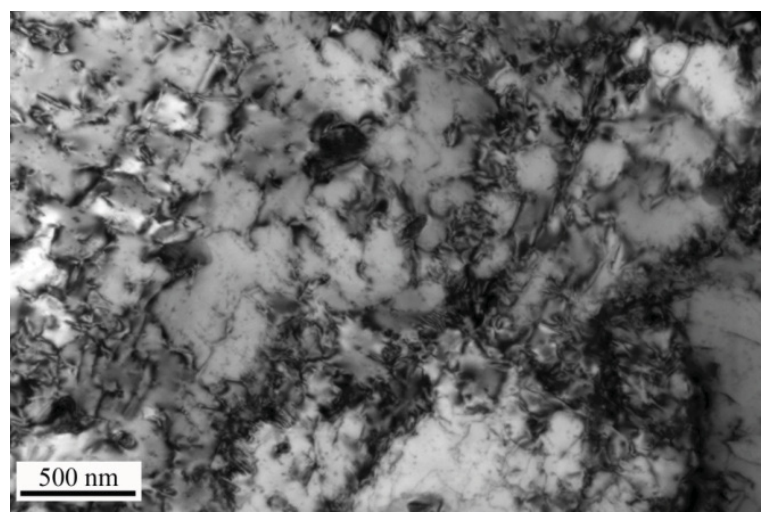

(d)

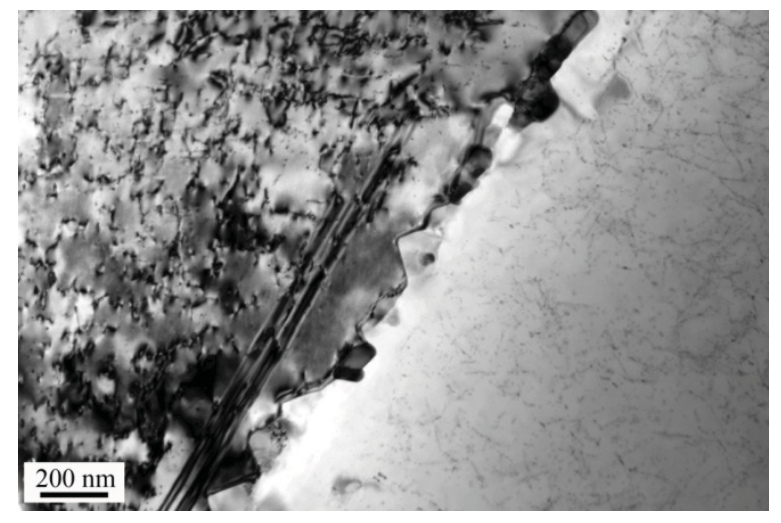

(e)

Figure 10. Bright field transmission electron microscope (TEM) images of the dislocation substructure formed during fatigue deformation of HT-UPS ( $a, b)$, creep fatigue deformation with a $3.6 \times 10^{3} \mathrm{sec}$ hold time (c, d), and a $1.8 \times 10^{3} \mathrm{sec}$ hold time (e). 


\section{DISCUSSION}

Typically, the addition of a hold time at peak tensile strain in strain-controlled fatigue testing will result in a reduced total number of cycles to failure. This was not the case, however, for the creep-fatigue conditions studied here for either 316 SS or HT-UPS; the addition of a hold time did not degrade the cycle life relative to continuous cycling. Justification for this degradation in cycle life in creep-fatigue is often attributed to a change in failure mode, which shifts from transgranular in pure fatigue to mixed mode or intergranular crack propagation in creep-fatigue cycling. In the current work, the negligible influence of the hold time on the cycle life is consistent with the absence of a change in cracking mode. In both the 316 SS and HT-UPS, whether with regard to fatigue or creep-fatigue specimens, none of the primary cracks propagated in mixed or intergranular modes - each exhibited purely transgranular propogation. The lack of a creep-fatigue interaction, cycles to failure, and transgranular cracking mode is consistent with previous creep-fatigue work conducted at $650{ }^{\circ} \mathrm{C}$ by Swindeman and Maziasz on an HTUPS alloy, AX-8 [7].

Despite the absence of an appreciable difference in fatigue and creep-fatigue resistance of $316 \mathrm{SS}$ and HT-UPS, the macroscopic deformation behavior, microstructural evolution (oxidation damage and interior grain boundary damage), and the post-deformation dislocation substructures were different. Each of these aspects is discussed with regard to its potential influence on the overall creep-fatigue resistance.

\subsection{Macroscopic Deformation Behavior}

The rapid cyclic hardening exhibited for HT-UPS in Figures 4 and 5 suggests that extensive precipitation of the ultrafine MC phase occurs during the first 100 strain cycles, whether in fatigue or creep-fatigue. Fine MC precipitates have not yet formed in the as-received material despite the presence of a discernable dislocation density remaining from the hot rolling operation. This observation is consistent with previous work on AX-5, an HT-UPS alloy of similar composition [6]. After a solutionannealing treatment at $1250^{\circ} \mathrm{C}$, Todd and Ren reported the exclusive presence of larger precipitates, which were classified as likely remnants of carbonitrides, and no dispersion of fine MC precipitates [6]. Aging of the AX-5 for 10 hours at $700^{\circ} \mathrm{C}$ resulted in an extensive amount of fine $\mathrm{MC}$ precipitates, whereas aging at the reduced temperature of $600^{\circ} \mathrm{C}$ revealed the presence of relatively few $\mathrm{MC}$ precipitates even after 300 hours [6]. Despite the absence in the as-received state, the nano-scale MC phase likely precipitated relatively quickly at the $650^{\circ} \mathrm{C}$ test temperatures when the application of cyclic strains introduced the necessary density of matrix dislocations. Further work will endeavor to extract the nucleation condition driving precipitate formation with regard to dislocation-dislocation interactions. While coplanar dislocation arrays resulting from uniaxial rolling operations may not provide the requisite driving force for $\mathrm{MC}$ coalescence and precipitation, the rapid buildup of dislocation tangles with larger strain fields resulting from proximate jogs and kinks might provide the necessary impetus for formation and growth.

The carbide size and distribution is clearly the controlling factor for the differences in post-deformed dislocation substructures of the austenitic alloys. $\mathrm{M}_{23} \mathrm{C}_{6}$ precipitates formed extensively along the grain boundaries, but were present in both alloys and could not have been a significant factor in the observed structure dissimilarities. HT-UPS, however, with its extensive distribution of nano-scale MC precipitates approximately $5 \mathrm{~nm}$ in diameter, clearly had the presence of a secondary phase structure that would provide for structural differences in the austenitic matrix following creep-fatigue deformation at $650^{\circ} \mathrm{C}$. These nano-scale precipitates are also relatively consistent in size with the $2.6 \mathrm{~nm} \mathrm{MC}$ precipitates observed in cold-worked (5.6\%) HT-UPS (AX-5) at $700^{\circ} \mathrm{C}$ after $1 \mathrm{hr}$ and the $8.7 \mathrm{~nm}$ precipitates seen after 3000 hours [6]. 


\subsection{Microstructural Evolution}

Another dramatic difference between the creep-fatigue deformed microstructures of the two alloys is the amount of interior or bulk material grain boundary damage. Interior grain boundary cracking or cavitation is a result of the deformation processes occurring during the creep portion of the cycle $[9,10]$; such cavitation was not observed in the continuous cycle fatigue specimens. The lesser amount of interior grain boundary damage in the HT-UPS specimens provides direct evidence of the alloy's improved creep resistance. Regardless, the grain boundary damage likely does not influence the overall creep-fatigue process as the cracking was transgranular in nature. The suggestion is therefore that the increase in high temperature strength and creep resistance in HT-UPS does not necessarily translate into an appreciable improvement in the creep-fatigue resistance, at least under these specific test conditions. The lack of improvement in the cyclic behavior may be attributable to the actual test conditions investigated, as there is an associated lack of intergranular crack propagation and quantifiable creep-fatigue interaction.

Another factor limiting substantial improvement could be related to the relatively poor oxidation resistance of the HT-UPS when compared to the 316 SS. As mentioned previously, the HT-UPS alloy exhibit a considerable amount of oxidation along the surface cracks. While there is little information available on the oxidation behavior of HT-UPS, the presence of oxide pegs were reported after extended time creep tests [4]. Compared to the CD 316 SS in Figure 7(a), the HT-UPS tested with a 3.6x10 3 sec hold time exhibits a thick oxide layer along both the specimen surface and surface-initiated cracks as can be seen in Figures 7(b) and 8. The oxide within a secondary crack is greater than $200 \mu \mathrm{m}$ in thickness under these conditions. It should be noted that the cycled specimens (316 SS and HT-UPS) were not cooled immediately following testing and spent some period of time at temperature following cycling, so some degree of oxide buildup may be attributable to sustained high-temperature exposure following the completion of the specific test. As was observed in other studies [3], extensive oxide pegging was observed in the $1.8 \times 10^{3}, 3.6 \times 10^{3}$, and $9.0 \times 10^{3} \mathrm{sec}$ for the HT-UPS specimens. Despite the similar test durations, no such oxidation pegs were observed in $316 \mathrm{SS}$. The negative influence of the air environment and associated oxidation behavior may be responsible for the lack of a creep-fatigue improvement in HTUPS over 316 SS, despite its demonstrated improved creep resistance and decreased dislocation mobility. As the present intended use of HT-UPS is a structural material for liquid sodium fast reactors, the oxidizing environment seen during mechanical tests is not a practical concern. This work suggests that the degradation during fatigue or creep-fatigue of $316 \mathrm{SS}$ is influenced to a lesser degree than HT-UPS, in which the crack propagation may be accelerated by oxidation processes. In HT-UPS, however, the cyclic and creep damage may play a less significant role in overall failure lifetimes than the damage caused by an oxidizing environment.

\subsection{Dislocation Substructures}

It has been reported that the creep strength of HT-UPS alloys is significantly greater than conventional stainless steels - on the order of 100 times at $700^{\circ} \mathrm{C}$ - and that this improvement is directly attributable to the dispersion of nano-scale MC precipitates $[1,2]$. Considerable evidence was observed in this work supporting the conclusion that the dislocation substructures in the post-cyclically deformed HTUPS specimens are a major component of this improvement in creep strength. An equiaxed dislocation cell structure does not form in the cycled HT-UPS in the same manner as is observed in 316 SS. Instead, a matrix of tangled dislocation populations pinned by the fine $\mathrm{MC}$ precipitates what results in the microstructure resulting over the buildup of cyclic strain. In a manner similar to creep deformation [2, 3], the dislocation pinning and associated obstacles to dislocation motion prevent recovery and the resulting cellular structure from forming. Furthermore, the enhanced creep resistance of the HT-UPS alloy is evident from the relatively large amount of interior creep damage in the form of grain boundary cavitation and separation in the CD 316 SS as compared to HT-UPS. Further work on an HT-UPS alloy will include 
the investigation of the creep-fatigue behavior of HT-UPS in an inert environment to extract the role of oxidation versus the non-equilibrium pinned dislocation substructure on crack propagation.

\section{CONCLUSIONS}

Although this work is still in an early phase with regard to actual use of this particular variant of HTUPS in modern reactor designs, an understanding of the behavioral response when exposed to creepfatigue conditions is beginning to take shape. Based upon the work performed, the following significant conclusions can be drawn:

1) No creep-fatigue interaction or associated decrease in cycle life was observed during fatigue of HT-UPS at $650^{\circ} \mathrm{C}$ and $1.0 \%$ total strain with the addition of hold times (creepfatigue) of up to $9 \times 10^{3} \mathrm{sec}$.

2) Ultra-fine MC phase was not present in as-received alloys subjected to a hot-rolled processing treatment alone, with no addition of cold work. The phase precipitated rapidly upon the application of cyclic strains as nucleation sites in the form of necessary dislocations were introduced.

3) The equaixed, cellular dislocation substructure that clearly formed in $316 \mathrm{SS}$ was completely absent in HT-UPS. Instead, dislocations were prevented from further migration into lower energy discrete networks as a result of extensive pinning by the dispersion of coherent nanoscale MC particles.

4) Intergranular surface oxidation was considerably worse in HT-UPS than 316 SS. The lack of a measurable increase in creep-fatigue life in HT-UPS is at least partly attributable to the deleterious oxidation response in test conditions that are not likely to be a factor in the applications for which this alloy is being evaluated.

Further work will provide detail into several of the pertinent additional variables that were identified during the course of this study. The role of local dislocation structures on the precipitation and growth of the fine MC particles will require complex evaluations of the microstructure during the first few deformation cycles under various conditions. Additionally, the specific role of environmental degradation on cyclic failure lifetimes will be qualified through controlled testing in a specially-designed environmental chamber having the ability to load specimens under approximated service conditions. Such topics are worthy of future efforts, as the promising nature of these alloys for specific nuclear or other power generation applications is becoming clear. 


\section{REFERENCES}

[1] Yamamoto, Y., Brady, M.P., Lu, Z.P., Maziasz, P.J., Liu, C.T., Pint, B.A., More, K.L., Meyer, H.M., and Payzant, E.A. "Creep-Resistant, $\mathrm{Al}_{2} \mathrm{O}_{3}$-Forming Austenitic Stainless Steels." Science 316433436 (2007).

[2] Maziasz, P. "Developing an Austenitic Stainless Steel for Improved Performance in Advanced Fossil Power Facilities." Journal of Materials (July), 14-20 (1989).

[3] Maziasz, P.J. and Swindeman, R.W., "Modified 14 Cr-16 Ni Stainless Steels with Improved Creep Resistance at $700^{\circ} \mathrm{C}$ Due to Tailored Precipitate Microstructures," Advances in Material Technology for Fossil Power Plants, ed. R. Viswanathan and R.I. Jaffee (Metals Park, OH: ASM, 1987).

[4] Swindeman, R.W., Maziasz, P.J., and Judkins, R.R., "Investigations of Alloys for Advanced Steam Cycle Superheaters and Reheaters," paper presented at $2^{\text {nd }}$ International Conference on Improved Coal-Fired Power Plants, Palo Alto, CA (Nov. 2-4, 1988).

[5] Maziasz, P.J. and Jitsukawa, S., "Minor Compositional Variations of Austenitic PCA to Explore MC Formation and Stability Characterisitics for Improved Radiation Resistance," ADIP Semiann. Prog. Rept., DOE/ER-0045/14, U.S. Department of Energy, Washington, D.C. (1985).

[6] Todd, J.A. and Ren, J., "Microstructural Studies of Advanced Austenitic Steels", ORNL/Sub/87SA663C, Nov. 15, 1989.

[7] Swindeman, R.W. and Maziasz, P.J., "High-Strength Austenitic Stainless Steel Tubing," in Pressure Vessel Technology, Verband der Technischen Uberwacgungs-Vereine, Essen, 1388-1404 (1992).

[8] ASTM Standard E606-04, "Standard Practice for Strain-Controlled Fatigue Testing," ASTM International.

[9] ASTM Standard E2714-09, "Standard Method for Creep-Fatigue Testing," ASTM International.

[10] Rodriguez, P. and Rao, K.B.S., "Nucleation and Growth of Cracks and Cavities under Creep-Fatigue Interaction," Progress in Materials Science 37 403-480 (1993).

[11] Hales, R., “A Quantitative Metallographic Assessment of Structural Degradation of Type 316 Stainless Steel during Creep-Fatigue," Fatigue Eng Mater Struct vol. 3(4) 339-356 (1980). 